\title{
Increased Circulating Soluble CD14 Is Associated with High Mortality in Gram-Negative Septic Shock
}

\author{
Regine Landmann, Werner Zimmerli, \\ Sebastiano Sansano, Susanne Link, Alfred Hahn, \\ Michel Pierre Glauser, and Thierry Calandra*
}

\begin{abstract}
Divisions of Infectious. Diseases and Hypertension (Departments of Research and Medicine), University Hospiral. Basel: Division of Infectious Diseases (Department of Internal Medicine). Centre Hôpital
\end{abstract} Universitaire, Lausanne, Switzerland

\begin{abstract}
The soluble glycoprotein sCD14 binds lipopolysaccharide, a complex that activates endothelial cells and that may be crucial in gram-negative sepsis. Therefore, serum sCD14 was analyzed in 54 patients with gram-negative septic shock and in 26 healthy controls. SCD14 was tested by ELISA and Western blotting. Patients had higher sCD14 concentrations than controls (median, $3.23 \mathrm{vs.} 2.48 \mu \mathrm{g} / \mathrm{mL}, P=.002$ ). Increased levels were associated with high mortality (median, 4.2 $\mu \mathrm{g} / \mathrm{mL}$ in nonsurvivors vs. $2.8 \mu \mathrm{g} / \mathrm{mL}$ in survivors, $P=.001) . \mathrm{sCD} 14$ was found in two isoforms (49 and $55 \mathrm{kDa}$ ) in monocyte cultures. In sera only one of either form was detectable. Controls had the 49-kDa form, and patients had either the 49- or 55-kDa form, but patients with high levels of sCD14 had only the 55-kDa form. Twenty-one (53\%) of 39 with the 55-kDa form and 8 (57\%) of 14 with the $49-\mathrm{kDa}$ form died. Thus, the level of SCD14 but not its biochemical form had a prognostic value in patients with gram-negative septic shock.
\end{abstract}

Lipopolysaccharide (LPS) plays a key role in the pathophysiology of sepsis [1]. The LPS receptor on myeloid cells is the phosphatidylinositol-linked membrane glycoprotein CD14 [2]. CD14 occurs in a membrane-associated form and as a soluble (s) molecule [3,4]. sCD14 is derived from the monocytic cell line Mono-Mac 6 in two forms [5]: A 48-kDa form is shed from the membrane of monocytes and MonoMac 6 cells $[6,7]$, and a 56-kDa form is detectable in metabolically labeled Mono-Mac 6 cells and in sCDI4 purified from urine $[3,5]$. The serum concentration of SCDI 4 is $\sim 1$ millionfold higher than that of cytokines [8]. Although much is known about cytokine liberation during experimental endotoxemia or sepsis, little is known about sCDI4 in these conditions [9-12]. Because CDI4 is the principle LPS receptor, the serum concentration of SCDI 4 may be modified during endotoxemia or sepsis. The physiologic role of $\mathrm{sCDI} 4$ is unknown. It could act as a scavenger by neutralizing circulating LPS [13] or, alternatively, it may play a harmful role by transmitting LPS effects on endothelial cells, which do not express membrane CDI4 [14]. Indeed, it was recently

Received 4 May 1994: revised 22 September 1994.

Presented in part: annual meeting. Infectious Diseases Society of America. New Orleans, October 1993 (Clin Infect Dis 1993:17:531).

Informed consent was obtained from all patients studied. The study was approved by the Ethical Committee. University Hospital, Basel, in accordance with the guidelines of the Swiss Academy for Medical Science.

Grant support: Swiss National Foundation (31-32310.9l)

Reprints or correspondence: Dr. Regine Landmann. Division of in fectious Diseases. Dept. of Research. University Hospital, CH-403I Basel. Switzerland.

* Present affiliation: Picower Institute of Medical Research, Manhasset, New York.

The Journal of Infectious Diseases 1995;171:639-44

(C) 1995 by The University of Chicago. All righis reserved.

$0022-1899 / 95 / 7103-0017 \$ 01.00$ shown that complexes of SCDI 4 with LPS activate these cells $[14,15]$.

We measured sequential serum concentrations of sCD14 in 54 patients with gram-negative septic shock, compared these with levels in normal controls, and correlated SCDI4 levels with patient outcome. We also determined the biochemical form of serum sCD14 by Western blotting and compared it with sCD14 derived from normal monocytes.

\section{Methods}

Patients. The study population comprised 54 patients ( 33 males, 21 females) with documented gram-negative septic shock. Their median age was 58 years (range, 7-78). All were part of a previously described study that compared the efficacy of J5 hyperimmunoglobulin $(n=22)$ with standard intravenously (iv) administered IgG $(n=32)$ (Sandoglobulin; Sandoz Pharmaceuticals, Basel, Switzerland) [16]. The etiology of septic shock was established by the isolation of gram-negative bacteria from blood in 37 patients (69\%). Of these, 30 had monomicrobial and 7 had polymicrobial bacteremia. Seventeen patients $(31 \%)$ had documented gram-negative infections with negative blood cultures. At study entry, the median duration of shock was $10 \mathrm{~h}$ (range, 2-144), the median urinary output was $5 \mathrm{~mL} / \mathrm{h}$ (range, 0-190), and the median arterial pH was 7.37 (range, 7.17-7.57). Blood was obtained from all patients at study entry (day 0 ), $2 \mathrm{~h}$ later (after infusion of either standard or J 5 hyperimmunoglobulin), and after $24 \mathrm{~h}$ and 10 days. In addition, 26 healthy controls ( 16 men, 10 women; median age, 48 years; range, 27-72) and 2 women with paroxysmal nocturnal hemoglobinuria (ages 30 and 38 years) were investigated. Sera were aliquoted and kept at $-70^{\circ} \mathrm{C}$ until analyzed.

Cells. Mononuclear leukocytes were isolated from heparinized blood by density gradient centrifugation over a ficoll-hypaque gradient. Monocytes were purified from mononuclear leukocytes by centrifugation over a continuous Percoll density 
gradient as described [17]. Cells were taken up in RPMI medium with 5\% heat-inactivated human AB serum before being labeled with $\left[{ }^{35} \mathrm{~S}\right]$ methionine or ${ }^{125} \mathrm{I}$. They were cultured for $48 \mathrm{~h}$ in serum-free HB101 medium (Hana Biologics, Alameda, CA) substituted with $2 \%$ human serum albumin and $10^{-8} M 1,25 \alpha^{-}$ dihydroxyvitamin $D_{3}$ before the supernatant was harvested for Western blotting.

Reagents, antibodies to CD/4, and recombinant (r) sCD14. Goat polyclonal anti-CD14 antiserum was a gift of R. Ulevitch (Scripps Research Institute, La Jolla, CA). We used the following mouse monoclonal antibodies: MEM 18 (IgGl, which recognizes membrane CDI4 and both forms of sCD14; gift of $\mathrm{V}$. Bazil, Prague [3]); RoMol (IgG2a; IBL, Hamburg, Germany) [18], 63D3 (IgG1), and 3C10 (IgG2b; both purified by affinity chromatography from hybridoma culture supernatants; American Type Culture Collection, Rockville, MD); and My4 (IgGI) (Coulter, Luton, UK). rsCDI4 was immunopurified on immobilized $3 \mathrm{C} 10$ from culture supernatants of $\mathrm{CHO}$ cells that were transfected with an expression vector containing truncated CDI 4 cDNA (unpublished data).

The endotoxin content in the stock solutions of antibodies was $<100 \mathrm{pg} / \mathrm{mL}$, as determined by quantitative limulus assay (Chromogenix, Mölndal, Sweden).

$s C D / 4$ depletion from serum. The antibody to CD1463D3 was coupled to $\mathrm{CNBr}$-activated Sepharose. Human AB serum containing $3 \mu \mathrm{g} / \mathrm{mL} \mathrm{sCDl} 4$ was absorbed to antibody-CNBr-Sepharose overnight at $4^{\circ} \mathrm{C}$. After centrifugation, no $\mathrm{SCD} / 4$ was detected by ELISA or Western blot in the sCDI4-depleted serum. Heat inactivation of normal serum at $56^{\circ} \mathrm{C}$ for $30 \mathrm{~min}$ also destroyed SCD14 immunoreactivity.

Assay for sCDI4. Serum concentrations of sCD14 were determined by sandwich ELISA. Polystyrene plates (Greiner 96well; Microlon, Frickenhausen, Germany) were coated overnight at room temperature with $2 \mu \mathrm{g} / \mathrm{mL}$ MEM 18 ( $50 \mu \mathrm{L} /$ well). After plates were washed three times with PBS and $0.05 \%$ Tween (wt/vol), nonspecific binding was blocked for $1 \mathrm{~h}$ at room temperature with $50 \mu \mathrm{L} /$ well $0.2 \mathrm{M}$ TRIS-HCl buffer (pH 7.5) with $1 \%$ bovine serum albumin (BSA: wt/vol) and $0.05 \%$ Tween (wt) vol). Serum samples diluted $1: 150,1: 300$, and $1: 600$ in $0.1 M$ phosphate buffer ( $\mathrm{pH} \mathrm{7.2)}$ with $1 \%$ BSA and $0.05 \%$ Tween (wt) vol) or standards (dilutions of $\mathrm{SCDl} 4$ isolated from serum by affinity chromatography [19]; $50 \mu \mathrm{L} /$ well) were incubated for 3 $h$ at room temperature. Plates were washed three times with PBS and $0.05 \%$ Tween. Captured sCD1 4 was measured by peroxidase-coupled RoMol (2-h incubation, $50 \mu \mathrm{L} /$ well, in $0.1 M$ phosphate buffer [pH 7.2] with $1 \%$ BSA and $0.05 \%$ Tween). The signal was detected using tetramethylbenzidine and read at $A_{450}$ in an ELISA reader (Molecular Devices, Palo Alto, CA).

The serum concentration of $\mathrm{sCD} 14$ was the weighted average of the concentrations determined for each dilution by extrapolation from the linear part $(3-40 \mathrm{ng} / \mathrm{mL})$ of the standard sCD14 curve. When $5 \mu \mathrm{g} / \mathrm{mL}$ LPS was added to the sCD 14 serum standard, serum sCD14 values did not change. For detection of sCD 14 in monocyte culture supernatants, a similar ELISA with $63 \mathrm{D} 3$ as a primary antibody $(100 \mu \mathrm{L}, 5 \mu \mathrm{g} / \mathrm{mL})$ and peroxidaselabeled $3 \mathrm{Cl} 10(500 \mathrm{ng} / \mathrm{mL})$ as a capturing antibody was used: purified rsCD14 (0.3-10 ng/mL) from CD 14-transfected CHO cells (unpublished data) served as a standard.
The specificity of the assay was confirmed by the following experiments. SCD 14-depleted human serum (see above) showed no reactivity in the ELISA. The immunoreactivity was recovered when the eluted SCDI 4 was added back to the depleted serum. In addition, the specificity of the second peroxidase-labeled antibody was tested by adding it along with unlabeled CDI4 antibody My4 to normal and sepsis sera. My4 competitively inhibited the binding of RoMol and of $3 \mathrm{ClO}$ (data not shown).

Effect of standard and $J 5$ hyperimmunoglobulin on $\mathrm{SCD} / 4$ determination. Patients were treated with standard iv $\operatorname{lgG}(200$ $\mathrm{mg} / \mathrm{kg}$ ) or the same dose of an anti-LPS hyperimmunoglobulin (J5) within 2 h of diagnosis of septic shock. The sCDI 4 content of the immunoglobulins given and their influence on sCDI4 serum values were evaluated. Standard IgG, at a twofold higher concentration than the serum IgG level measured after patients received therapy $(12 \mathrm{mg} / \mathrm{mL})$, contained $100 \mathrm{ng} / \mathrm{mL}$ sCD $14 . \mathrm{J} 5$ hyperimmunoglobulin at $12 \mathrm{mg} / \mathrm{mL}$ contained $5 \mathrm{ng} / \mathrm{mL}$ sCD 14. When either immunoglobulin preparation was added to sCD14 standard pooled human serum or sCD14-free serum, the optical densities of the preparations increased by the amount of sCD 14 in standard IgG or $\mathbf{J} 5$ hyperimmunoglobulin.

sCDl 4 levels were determined in the 26 healthy controls. The median serum concentration of $\mathrm{sCD} 14$ was $2.48 \mu \mathrm{g} / \mathrm{mL}$ (range, $1.75-2.90)$, and intra- and interindividual coefficients of variation were $12 \%$ and $23 \%$, respectively ( $n=5$, repeated measurements at $0,2,24$, and $240 \mathrm{~h}$ ).

SDS-PAGE and Western blotting. Serum samples were diluted to contain $3 \mathrm{ng}$ of $\mathrm{SCD} / 4 / 10 \mu \mathrm{L}$ and were denatured by boiling for $5 \mathrm{~min}$ in $0.5 \mathrm{MTRIS}-\mathrm{HCl}$ containing 5\% SDS, $2.5 \%$ glycerol, and $0.01 \%$ bromphenol blue (sample buffer). Denatured proteins and prestained molecular mass standards (BioRad, Glattbrugg, Switzerland) were electrophoresed (200 V. $500 \mathrm{~mA}$ ) for $60 \mathrm{~min}$ in $7.5 \%$ polyacrylamide gels under nonreducing conditions and transferred for $60 \mathrm{~min}(100 \mathrm{~V}, 500 \mathrm{~mA})$ onto Immunlite membranes (Bio-Rad) presoaked in $25 \mathrm{mM}$ TRIS and $192 \mathrm{mM}$ glycine transfer buffer (TBS; pH 8.3) using a wet transblot system (Bio-Rad). Membranes were incubated overnight at $4{ }^{\circ} \mathrm{C}$ in TBS containing $7.5 \%$ dry milk to reduce nonspecific protein binding and washed twice with TBS and $0.05 \%$ Tween (TTBS). They were then incubated for $3 \mathrm{~h}$ at room temperature on a rocking platform with the monoclonal antibody to CD14 (3C10), diluted 1:400 in TTBS containing 1\% dry milk or with polyclonal goat anti-CDI4 antiserum diluted $1: 1000$. After being washed three times in TTBS, the membranes were incubated for $2 \mathrm{~h}$ at room temperature with alkaline phosphatase-conjugated goat anti-mouse IgG (1:3000; Bio$\mathrm{Rad})$ or mouse anti-goat IgG (1:10,000; Sigma, St. Louis) in TTBS containing $1 \%$ dry milk. The membranes were then washed three times with TTBS, incubated for $5 \mathrm{~min}$ with $5 \mathrm{~mL}$ of chemoluminescent substrate solution (adamantyl dioxetane phenyl phosphate; Bio-Rad) and exposed to Kodak X-Omat films for 10-30 $\mathrm{min}$.

Labeling with $\left[{ }^{35} \mathrm{~S}\right]$ methionine. Monocytes were incubated for $48 \mathrm{~h}$ in medium with $5 \%$ heat-inactivated AB serum. CDI4transfected CHO cells were cultured in serum-free RPMI medium containing G418 (Geneticin; Boehringer, Mannheim, Germany). Both cell types were washed and kept for $1 \mathrm{~h}$ in 
Table 1. Serum concentrations of soluble (s) CDI4 during and after septic shock.

\begin{tabular}{llll}
\hline & \multicolumn{2}{c}{$\mathrm{sCDI} 4(\mu \mathrm{g} / \mathrm{mL})$} \\
\cline { 2 - 3 } Serum sample & $\begin{array}{c}\text { Survivors } \\
(n=25)\end{array}$ & $\begin{array}{c}\text { Nonsurvivors } \\
(n=29)\end{array}$ & $P$ \\
\hline Study entry & $2.77(1.15-5.64)$ & $4.21(1.06-9.95)$ & .001 \\
2 h after study entry & $2.44(0.79-8.40)$ & $3.89(1.54-10.10)$ & .048 \\
Day 1 & $3.41(1.94-8.15)$ & $4.23(1.93-14.42)$ & .11 \\
Day 10 & $3.03(0.95-9.89)$ & $3.94(2.51-5.69)$ & .12 \\
Controls* & $2.48(1.75-2.90)$ & & \\
\hline
\end{tabular}

NOTE. Data are median (range) sCD 14 determination with ELISA. $* n=26$.

methionine-free medium supplemented with $2 \%$ dialyzed fetal calf serum before addition of $100 \mu \mathrm{Ci}$ of $\left[{ }^{35} \mathrm{~S}\right]$ methionine (Amersham Laboratories, Amersham, UK). After overnight culture, the supernatant was harvested, centrifuged at $100,000 \mathrm{~g}$ for 30 min at $4^{\circ} \mathrm{C}$; Nonidet P-40 and phenylmethylsulfonyl fluoride (Sigma) were added at final concentrations of $0.5 \%$ and $2 \mathrm{mM}$, respectively. For preclearing, the supernatant was incubated 30 min at $4^{\circ} \mathrm{C}$ with protein G-Sepharose (Pharmacia, Piscataway, $\mathrm{NJ}$ ) in the presence of normal serum. After centrifugation, the supernatant was first incubated for $60 \mathrm{~min}$ at $4^{\circ} \mathrm{C}$ with $3 \mathrm{Cl} 0$ and then for $30 \mathrm{~min}$ at $4^{\circ} \mathrm{C}$ with protein $\mathrm{G}$-Sepharose. The immunoprecipitate was washed three times in $50 \mathrm{~m} M$ TRIS, $150 \mathrm{~m} M \mathrm{NaCl}$, and $5 \mathrm{mM}$ EDTA buffer ( $\mathrm{pH} 7.3$ ). The sample was taken up in buffer and then denatured and electrophoresed in a $7.5 \% \mathrm{SDS}$-polyacrylamide gel as described above. Gels were fixed for $30 \mathrm{~min}$ in Amplify solution (Amersham Laboratories, Amersham, UK) and then washed in distilled water, dried, and autoradiographed.

Labeling with ${ }^{25.5}$. Freshly isolated monocytes $\left(2.5 \times 10^{6}\right)$ were washed three times with PBS, iodinated for $15 \mathrm{~min}$ at room temperature with $500 \mu \mathrm{Ci}$ of $\mathrm{Na},{ }^{125} \mathrm{I}$, and Iodobeads (Pierce, Rockford, IL) in 6-well culture plates, washed again with PBS, and cultured overnight in RPMI medium with $5 \%$ heat-inactivated human $A B$ serum. The chase medium was then harvested and processed as described for the $\left[{ }^{35} \mathrm{~S}\right] \mathrm{methionine-labeled} \mathrm{su-}$ pernatant.

Statistics. Patient groups and controls were compared by Mann-Whitney test. The relationship between different serologic parameters was evaluated by Wilcoxon rank correlation test. The effect of SCD 4 , tumor necrosis factor- $\alpha$ (TNF- $\alpha$ ), and age on mortality was studied by multivariate analysis of variance (Superanova; Abacus, Berkeley, CA)

\section{Results}

sCDI 4 concentrations in sera of patients with gram-negative septic shock. Serum sCDl4 concentrations were higher in the 54 patients with gram-negative septic shock than in 26 healthy controls (median, 3.23 vs. $2.48 \mu \mathrm{g} / \mathrm{mL} ; P=.002$ ). Among the 54 patients with gram-negative septic shock, 29 (53.8\%) died. The clinical course of the patients has been described [16]. A high sCD14 level at the onset of shock was associated with poor outcome. As shown in table 1, nonsur- vivors showed significantly higher median sCDl 4 concentrations than survivors. This difference was significant at study entry $(P=.001)$ and 2 h later but not after 1 and 10 days. The sCD14 level remained predictive for a high mortality when age and TNF- $\alpha$ were included in a multivariate analysis $(P<.01)$.

Relationship between sCDI4 and clinical parameters or cylokines. The earliest measure of sCD 14 correlated inversely with mean arterial pressure at that time $(P=.03)$ but did not correlate with duration of shock at entry $(P=.90)$ or with urinary output $(P=.86)$. In addition, it did not correlate with TNF- $\alpha(P=.77)$, interleukin (IL)-1 $\beta(P=.44)$, IL-6 $(P=.79)$, interferon (IFN)- $\gamma(P=.95)$, or IFN- $\alpha(P=$ 69). Serum levels of these cytokines have been described $[11,12]$.

Isoforms of SCD14. The monocytic cell line Mono-Mac 6 releases two $\mathrm{sCD} 14$ forms [5], and in sCD 4 purified from urine two forms are identified under reducing conditions [3, 8]. However, the expression of two CDI4 isoforms has not been seen in normal monocytes, which are the major source of serum sCD14. We therefore analyzed culture supernatants of membrane or metabolically labeled monocytes by immunoprecipitation and compared them with immunoblots of 48 -h monocyte culture supernatants (figure 1). The smaller ( $49 \mathrm{kDa}$ ) form of $\mathrm{sCD} 14$ was derived from the membrane, since it was the only molecule detectable in supernatants of ${ }^{125}$ I-labeled monocytes (figure 1, lane 2). In contrast, both the larger $(55 \mathrm{kDa})$ and to a lesser extent the smaller forms were found in supernatants of metabolically labeled cells (figure 1, lane 3 ). This suggests that the $55-\mathrm{kDa}$ form has an intracellular origin without membrane attachment.

\section{monocyte}

\section{rsCD14 sCD14}

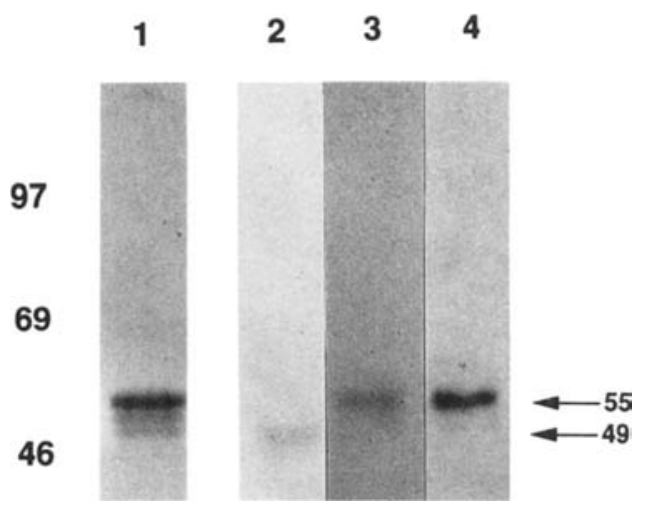

Figure 1. Biochemical analysis of $\mathrm{SCD} 14$. By lane: 1 , supernatant containing $\left[{ }^{35} \mathrm{~S}\right]$ methionine-labeled recombinant $\mathrm{SCD} 14 ; 2$, supernatant from ${ }^{125}$ I-labeled monocytes after overnight culture; 3 , supernatant of monocytes after overnight metabolic labeling; 4 , Western blot of 48-h serum-free monocyte culture supernatant. 


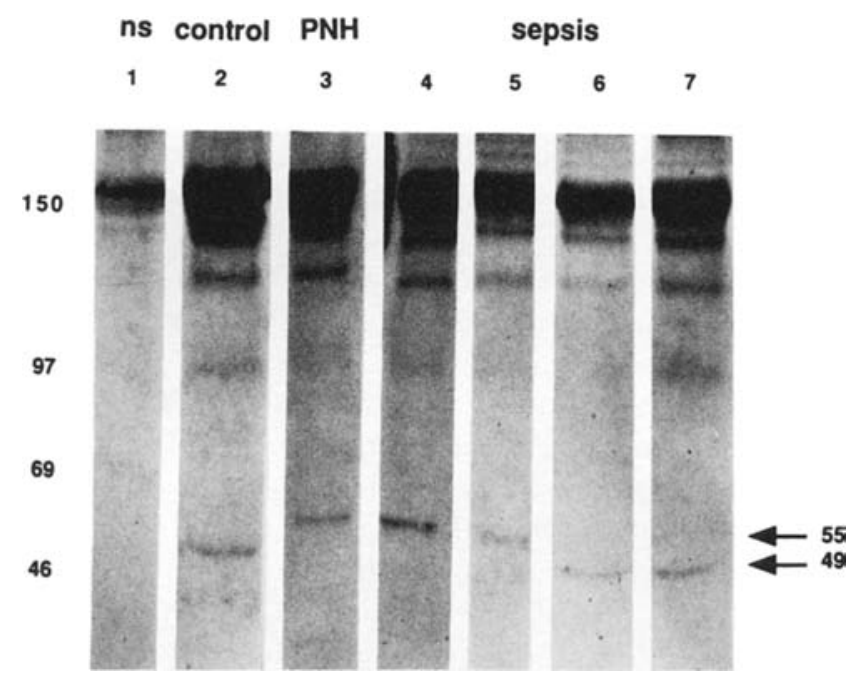

Figure 2. Western blots from sera. By lane: 1, nonspecific (ns) binding, blot with alkaline phosphatase-conjugated second antibody: 2, serum from healthy control; 3, serum from paroxysmal nocturnal hemoglobinuria $(\mathrm{PNH})$ patient; $4-7$, sera from sepsis patients at study entry (lanes 4 and 5, 55-kDa sCD14, survivor and nonsurvivor, respectively; lanes 6 and 7,49-kDa sCD14, survivor and nonsurvivor, respectively).

Finally, in Western blots of serum-free monocyte culture supernatants, the 55-kDa form was clearly seen; the smaller forms gave only a weak signal (figure 1, lane 4). To document the existence of the two CD14 isoforms, the immunoprecipitate from metabolically labeled culture supernatant of CD14-transfected CHO cells is shown on lane 1 in figure 1 . In this supernatant, which was very rich in SCD14 $(2 \mu \mathrm{g} /$ $\mathrm{mL})$, the upper band $(55 \mathrm{kDa})$ was stronger than the $49-\mathrm{kDA}$ band and even a third intermediate form of SCDI 4 could be detected.

Western blot of sera. After recognizing that rsCD14 and monocyte culture-derived CD 4 both exist in two molecular forms, we analyzed human sera to see if it also contained both forms. For this purpose, Western blots were made with 26 sera from healthy controls and with sera from the 54 study patients. Serum from 1 patient gave no signal in Western blot; therefore, the analysis includes 53 patients. As shown in lane 2 of figure 2, the 49-kDa form of $\mathrm{sCD} 14$ was found in serum from healthy volunteers. In contrast, patients with septic shock had either the 49- or the 55-kDa form at study onset, provided that their sCD14 level remained $<3.5 \mu \mathrm{g} /$ $\mathrm{mL}$ (figure 2 shows two examples of the $49-\mathrm{kDa}$ form, lanes 6 and 7). An sCD1 4 level $>3.5 \mu \mathrm{g} / \mathrm{mL}$ was exclusively associated with the $55-\mathrm{kDa}$ form of $\mathrm{sCD} 14$ (figure 2, lanes 4 and 5). The difference in molecular mass was also seen when a polyclonal instead of a monoclonal antibody was used for immunoblotting (data not shown). In addition, sera from patients with paroxysmal nocturnal hemoglobinuria (who lack membrane CD14 and therefore cannot release the smaller form of $\mathrm{sCDI} 4$ ) had the 55-kDa form exclusively (figure 2, lane 3).

Relationship between $\mathrm{SCD} 14$ molecular form and concentration. To determine clinical conditions associated with predominance of either form of $\mathrm{sCD} 14$, patients were grouped by sCDI 4 form and serum concentrations at onset of shock. Elevated SCD14 concentrations were associated with a 55$\mathrm{kDa}$ sCD 4 (figure 3). Patients with 55-kDa sCD14 had median $\mathrm{sCD} 14$ concentration of $3.43 \mu \mathrm{g} / \mathrm{mL}$ (range, $1.41-$ 9.95); those with the 49-kDa form had a median SCD14 of $2.28 \mu \mathrm{g} / \mathrm{mL}$ (range, $1.06-2.90 ; P<.001$ ). The molecular form of SCD 4 by itself was not associated with high mortality; 21 (53\%) of 39 with 55-kDa SCDI 4 and 8 (57\%) of 14 with the 49-kDa form died (figure 3). All 26 healthy controls had 49-kDa sCD 14 (figure 3 ). Both patients with paroxysmal nocturnal hemoglobinuria had elevated levels of $55-\mathrm{kDa}$ CDI4 in their serum.

Immunoblot of CDI4 from sera of patients during sepsis. To detect a possible switch from one molecular form of sCDl 4 to the other, sera from 4 patients were analyzed consecutively at study entry and 2 and $24 \mathrm{~h}$ and 10 days later (figure $4 ; 2$ patients with $49-\mathrm{kDa} \operatorname{sCD} 14[\mathrm{~A}, \mathrm{C}]$ and 2 with $>3 \mu \mathrm{g} / \mathrm{mL} 55-\mathrm{kDa}$ sCD 4 [B, D]). In figure 4 , patients in the upper row survived; those in the lower row died. Each patient had the same form of $\mathrm{sCD} 14$ throughout the observation period, that is, no switch in CDI4 isoforms was observed.

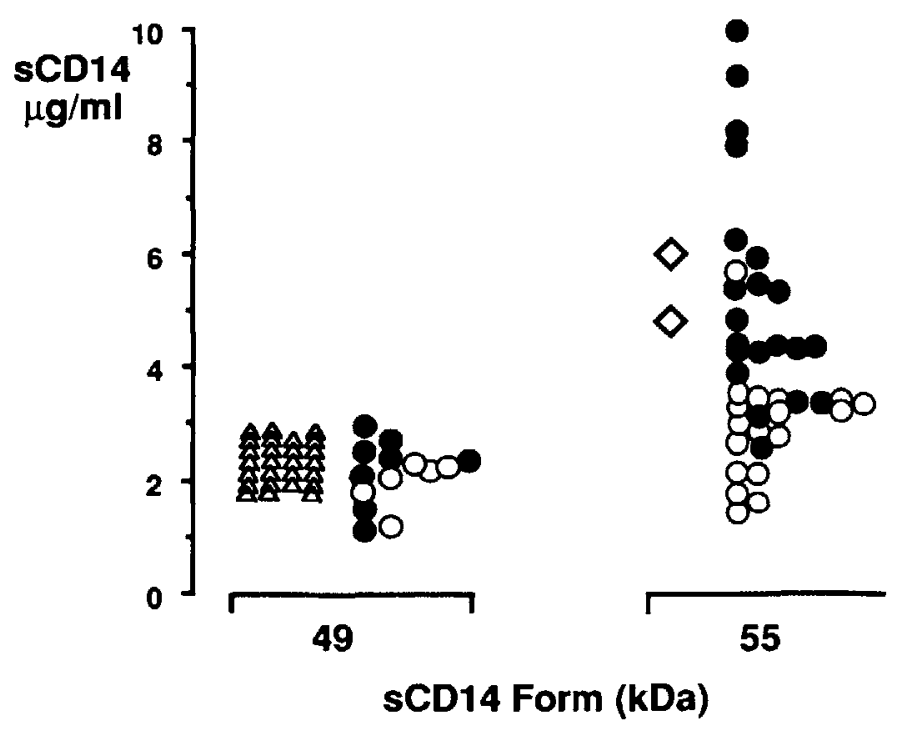

Figure 3. Relationship between sCD 4 concentration and molecular forms. Left: $\triangle, 26$ healthy controls, 14 sepsis patients with $49-\mathrm{kDa}$ form (6 survivors [O], 8 nonsurvivors [0]). Right: 2 patients with paroxysmal nocturnal hemoglobinuria $(\diamond)$ and 39 sepsis patients with $55-\mathrm{kDa}$ form ( 18 survivors [O], 21 nonsurvivors [0]). Serum from 1 of 54 patients did not give a signal in Western blot. 


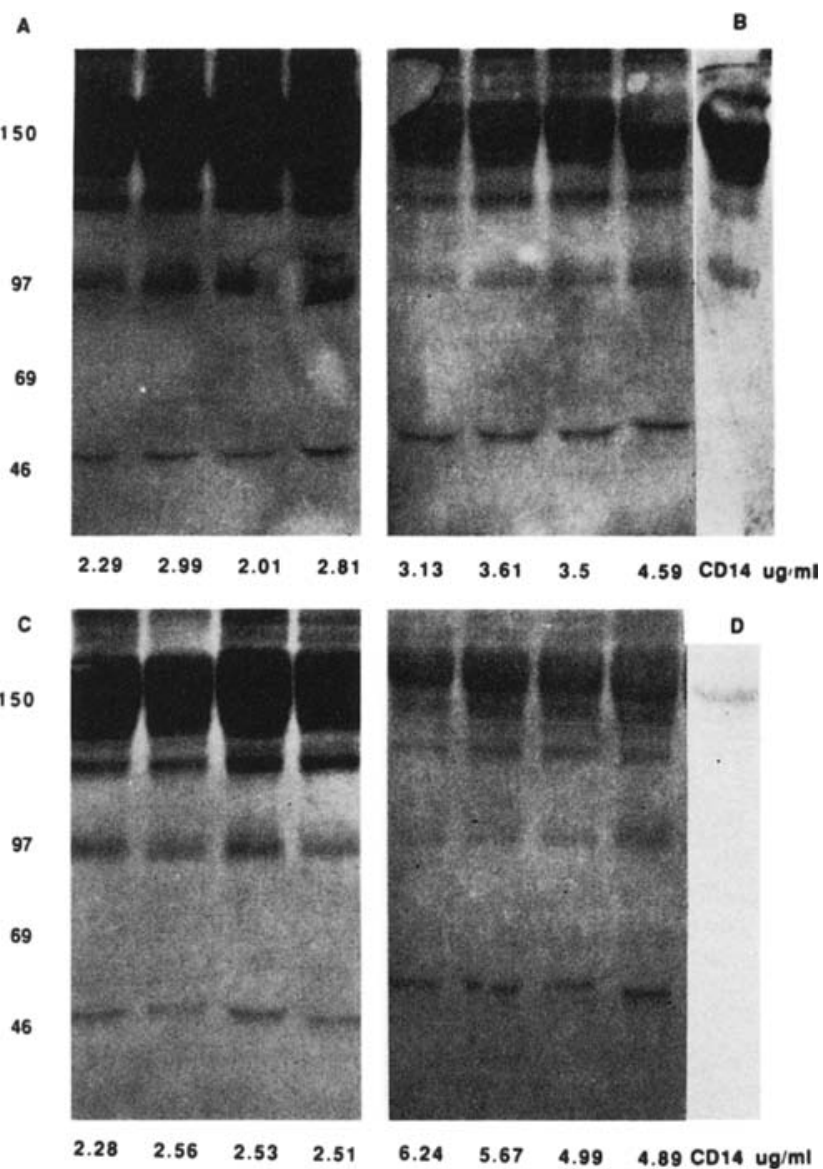

Figure 4. Western blots and $\mathrm{sCD} / 4$ concentrations during and after septic shock. A and B, Survivors with 49- and 55-kDa forms, respectively. $C$ and $\mathbf{D}$, Nonsurvivors with $49-$ and $55-\mathrm{kDa}$ forms, respectively. Far right of $\mathbf{B}$ and $\mathbf{D}$ : nonspecific binding in serum with alkaline phosphatase-conjugated second antibody.

\section{Discussion}

In the present study, serum concentrations and biochemical forms of SCDI 4 were investigated in patients with gramnegative septic shock. They had elevated serum SCDI 4 concentrations. In addition, the CDI4 derived from normal monocytes was found in 49 - and 55-kDa forms that originate from the cell membrane and the intracellular space. In serum, only a single form was detectable. High levels of sCD14 were associated with expression of the 55-kDa form. The serum concentration but not the isoform of $\mathrm{SCD} 14$ was predictive for death.

Soluble CDI4 is spontaneously released by the MonoMac 6 cell line, by monocytes, macrophages, and granulocytes $[5,7,17,20]$. After release, sCD14 circulates in the bloodstream [8]. Whereas the serum concentration of sCD14 is constant in normal persons (see Methods), we found increased levels in patients with gram-negative septic shock. This could be due to a reduced SCD 14 clearance or alternatively to enhanced liberation. The former is unlikely, since there was no relationship between urinary output and $\mathrm{sCD} 14$ concentration. The latter probably occurs during sepsis. The stimulus for SCD14 liberation may be LPS itself or a cytokine. We found that LPS enhances $\mathrm{SCD} 14$ release from normal monocytes in vitro (unpublished data). In contrast, we found no effect of TNF- $\alpha$, IL-1 $\beta$, IL- 6 , or IFN- $\gamma$ on sCD14 release in vitro [17].

The pathophysiologic significance of an increased SCD 14 concentration in septic shock is unknown, but it is associated with increased mortality. SCD14 promotes LPS binding to endothelial cells [15]. The ensuing activation of these cells may be detrimental and thus may explain the worse prognosis in patients with increased SCDI4. This relationship suggests that serum levels of SCDI 4 may be crucial for the fate of endothelial cells.

The existence of two forms of sCDI4 has been documented in immunoprecipitates isolated from urine [3]. We sought to find if the two isoforms are also detectable in serum. In earlier studies, only the smaller form was detected in monocytes $[6,20]$. Therefore, we investigated the cellular mechanisms of release by cells that are the major source of $\mathrm{sCD} 14$. For this purpose, we analyzed supernatants of monocytes by Western blotting and after membrane or metabolic labeling. We detected both forms.

The larger form predominated in supernatants of normal 48-h cultured monocytes. This conclusion is based on the Western blot analysis of concentrated supernatants. Since the cultures were serum-free, a contribution of serum CD14 could be excluded. In addition, the metabolic labeling revealed that in overnight cultures, the 55-kDa form was mainly synthesized. The origin of this larger form is unknown. Because it is slightly larger than the well-described membrane CD14 (54 kDa) [5], it may be released as a precursor before processing and attachment of the glycosyl phosphatidylinositol (GPI) anchor. This mechanism has been described for several other GPI-linked proteins [21]. Moreover, the immunoblot of sera from our patients with paroxysmal nocturnal hemoglobinuria, which lacked membrane CD14, showed the $55-\mathrm{kDa}$ form exclusively. We also found that the smaller form was derived from the membrane, since it was the only isoform detected in the supernatant after membrane labeling of viable monocytes. The 49-kDa form is smaller than membrane CD14, which confirms its proteolytic cleavage. In case of shedding by a GPI-specific phospholipase $C$, the molecular mass of membrane and sCD 4 would be identical. In addition, Bazil and Strominger [6] found that protease inhibitors reduced the release of membrane-derived small sCD14.

Sera from patients with gram-negative septic shock and controls had one of the two sCDI4 isoforms. In Western blots of patients with an $\mathrm{SCD} 14>3.5 \mu \mathrm{g} / \mathrm{mL}$, the $55-\mathrm{kDa}$ 
form was detected exclusively. In contrast, sera from healthy volunteers and from patients with sCD14 $<3.5 \mu \mathrm{g} / \mathrm{mL}$ contained either form. This difference was not an artifact; it appeared with a constant load of $3 \mathrm{ng}$ of $\mathrm{sCDl} 4$ per slot in the polyacrylamide gel. As outlined above, in healthy volunteers the smaller isoform of $\mathrm{sCDI} 4$ is membrane derived, and the larger form is from the intracellular space. One could argue that strong cell activation in septic patients results in the depletion of membrane CDI4. However, these cells could probably still secrete unprocessed $55-\mathrm{kDa} \mathrm{CD} 14$. In contrast, cells with normal surface CD14 may serve as reservoir for the shedding of the small isoform. Under culture conditions, normal monocytes preferentially released the $55-\mathrm{kDa}$ isoform, yet normal serum exclusively contained the 49-kDa form. This could indicate that a large pool of cells other than monocytes (e.g., macrophages or granulocytes) mainly contribute the 49-kDa form. In patients from whom we consecutively tested sCDI4 forms after septic shock, we found no changes from higher to lower molecular mass forms. Thus, the mechanisms that regulate the secretion of the isoforms of sCDI 4 remain unknown.

In conclusion, the serum level of $\mathrm{sCD} 14$ was a prognostic marker in gram-negative septic shock. The functional consequences of the elevated $\mathrm{sCD} 14$ concentration should be analyzed in an in vitro or in vivo model.

\section{Acknowledgments}

We thank Alois Gratwohl (Division of Hematology, University Hospital, Basel) for collaboration in the study of patients with paroxysmal nocturnal hemoglobinuria and Harald Gallati (Hoffman-La Roche, Basel) for help in setting up the CD14 ELISA.

\section{References}

1. Glauser MP, Zanetti G, Baumgartner JD, Cohen J. Septic shock: pathogenesis. Lancet 1991;338:732-6.

2. Wright SD. Ramos RA. Tobias PS, Ulevitch RJ, Mathison JC. CDI4, a receptor for complexes of lipopolysaccharide (LPS) and LPS binding protein. Science 1990;249:1431-3

3. Bazil V. Horejsi V. Baudys M. et al. Biochemical characterization of a soluble form of the 53-kDa monocyte surface antigen. Eur J Immunol 1986;16:1583-9.

4. Maliszewski CR, Ball ED, Graziano RF, Fanger MW. Isolation and characterization of My23, a myeloid cell-derived antigen reactive with the monoclonal antibody AML-2-23. J Immunol 1985; 135:1929-36.

5. Labeta MO. Durieux JJ, Fernandez N, Herrmann R, Ferrara P. Release from a human monocyte-like cell line of two different soluble forms of the lipopolysaccharide receptor, CDI4. Eur J Immunol 1993:23:2144-51.

6. Bazil V, Strominger JL. Shedding as a mechanism of down-modulation of CDI4 on stimulated human monocytes. J Immunol 1991; 147:1567-74.

7. Haziot A, Tsuberi BZ, Goyert SM. Neutrophil CDI4: biochemical properties and role in the secretion of tumor necrosis factor- $\alpha$ in response to lipopolysaccharide. J Immunol 1993;150:5556-65.

8. Bazil V. Baudys M. Hilgert I, et al. Structural relationship between the soluble and membrane-bound forms of human monocyte surface glycoprotein CD14. Mol Immunol 1989;26:657-62.

9. Spinas G, Bloesch D, Keller U. Zimmerli W. Cammisuli S. Pretreatment with ibuprofen augments circulating tumor necrosis factor- $\alpha$, interleukin-6, and elastase during endotoxemia. J Infect Dis 1991:163:89-95.

10. Billiau A, Vandekerckhove F. Cytokines and their interactions with other inflammatory mediators in the pathogenesis of sepsis and septic shock. Eur J Clin Invest 1991:21:559-73.

11. Calandra T, Baumgartner JD, Grau GE, et al. Prognostic values of tumor necrosis factor/cachectin, interleukin-I, interferon- $\alpha$, and interferon- $\gamma$ in the serum of patients with septic shock. J Infect Dis 1990:161:982-7.

12. Calandra T. Gerain J, Heumann D. Baumgartner JD, Glauser MP, Swiss-Dutch $\mathrm{J} 5 \mathrm{Immunoglobulin}$ Study Group. High circulating levels of interleukin- 6 in patients with septic shock: evolution during sepsis, prognostic value, and interplay with other cytokines. Am J Med 1991;91:23-9.

13. Schütt C, Schilling T, Grunwald U, Schönfeld W, Krüger C. Endotoxin-neutralizing capacity of soluble CD14. Res Immunol 1992;143:1-8.

14. Frey EA, Miller DS, Jahr TG, et al. Soluble CD14 participates in the response of cells to lipopolysaccharide. J Exp Med 1992;176:1665$7 !$

15. Pugin J. Schürer-Maly CC, Leturcq D. Moriarty A. Ulevitch RJ, Tobias PS. Lipopolysaccharide activation of human endothelial and epithelial cells is mediated by lipopolysaccharide-binding protein and soluble CD14. Proc Natl Acad Sci USA 1993;90:2744-8.

16. Calandra T, Glauser MP, Schellekens J. Verhoef J. Swiss-Dutch J5 Immunoglobulin Study Group. Treatment of gram-negative septic shock with human $\mathrm{IgG}$ antibody to Escherichia coli J5: a prospective. double-blind, randomized trial. J Infect Dis 1988;158:312-9.

17. Landmann R. Fisscher AE, Obrecht JP. Interferon-gamma and interleukin-4 downregulate soluble CD 14 release in human monocytes and macrophages. J Leukoc Biol 1992;52:323-30.

18. Schütt $C$, Ringel $B$, Nausch $M$, et al. Human monocyte activation induced by an anti-CD14 monoclonal antibody. Immunol Lett 1988; 19:321-8.

19. Grunwald U, Krüger C, Westermann J, Lukowsky A, Ehlers M, Schütt C. An enzyme-linked immunosorbent assay for the quantification of solubilized CD/4 in biological fluids. I Immunol Methods $1992 ; 155: 225-32$

20. Haziot A. Chen S. Ferrero E. Low GM. Silber R, Goyert SM. The monocyte differentiation antigen, $\mathrm{CD} 14$, is anchored to the cell membrane by a phosphatidylinositol linkage. J Immunol 1988; 141:547-52.

21. Kodukula K, Micanovic R, Gerber L, Tamburrini M, Brink L, Udenfriend $\mathrm{S}$. Biosynthesis of phosphatidylinositol glycan-anchored membrane proteins. J Biol Chem 1991;266:4464-70. 